\title{
Antimicrobial diterpenoids and triterpenoids from the stem bark of Croton macrostachys
}

\author{
Mathieu TENE ${ }^{1 *}$, Blanche Laure NDONTSA ${ }^{1}$, Pierre TANE ${ }^{1}$, \\ Jean de Dieu TAMOKOU ${ }^{2}$ and Jules-Roger KUIATE ${ }^{2}$ \\ ${ }^{I}$ Chemistry Department, University of Dschang, P.O Box 67, Dschang, Cameroon. \\ ${ }^{2}$ Biochemistry Department, University of Dschang, P.O Box 67, Dschang, Cameroon. \\ *Corresponding author, E-mail: mtene2001@yahoo.fr; Tel.: +237-77 808420
}

\begin{abstract}
Antimicrobial-guided fractionation of the EtOAc extract of the stem bark of Croton macrostachys afforded five known compounds including two lupane triterpenoids, lupeol (1) and betulin (2), and three clerodane diterpenoids, floridolide A (3), hardwickic acid (4) and 12-oxo-hardwickic acid (5). Their structures were elucidated on the basis of spectral studies and comparison with published data. The EtOAc extract and compounds 1, 2, 4 and 5 were evaluated for their antibacterial and antifungal activities by macro-dilution method. The extract displayed significant antibacterial and antifungal activities (MIC $=31.25-1000 \mu \mathrm{g} / \mathrm{ml}$ ). Betulin (2) and 12-oxo-hardwickic acid (5) were the most active compounds (MIC $=7.81-500 \mu \mathrm{g} / \mathrm{ml}$ ). The most sensitive microorganisms were Staphylococcus aureus ATCC 25922 for bacteria and two Candida species, Candida albicans ATCC 24433 and Candida krusei ATCC 6258, for fungi. The isolation of these active antibacterial and antifungal principles supports the use of $C$. macrostachys in traditional medicine for the treatment of microbial infections.
\end{abstract}

(C) 2009 International Formulae Group. All rights reserved.

Keywords: Croton macrostachys; Euphorbiaceae; triterpenes; diterpenes; antibacterial; antifungal.

\section{INTRODUCTION}

Croton macrostachys Hochst. (Euphorbiaceae) is a tree, 9 to $15 \mathrm{~m}$ high, distributed in mountainous forests and savannah of the tropical regions (Hutchinson and Dalziel, 1958). It is used in traditional medicine against many troubles such as jaundice, venereal diseases, skin itches (Getahun, 1976) and rheumatism (Yineger et al., 2008). It is also used as purgative (Getahun, 1976; Mazzanti et al., 1987) and as vermifuge (Getahun, 1976). The acid-ethanol and aqueous extracts of the bark of $C$. macrostachys were reported to possess antibacterial and antifungal activities (Palmeira Junior et al., 2006). Previous phytochemical studies have revealed that plant species of the genus Croton mainly produce diterpenoids (Krebs and Ramiarantsoa, 1997; Kapingou et al., 2000; Ngadjui et al., 2002; Block et al., 2004; Tane et al., 2004). Prior phytochemical investigation of $C$. macrostachys showed that it contains clerodane diterpenoids (Kapingou et al., 2000; Tane et al., 2004). The resistance of human pathogenic microorganisms to the major classes of antibiotics has increased in recent years, due to the indiscriminate use of antimicrobial drugs (Karaman et al., 2003). This has caused many clinical problems in the treatment of infectious diseases and the antibiotics commonly used are sometimes associated with adverse effects on the host, which include hypersensitivity, allergic reaction and immunosuppression (Mukherjee et al., 2002). The search for new antifungal 
and antibacterial agents from natural sources has intensified in response to the limitations of currently available therapy and the emergence of drug-resistant strains. It is also important to evaluate extracts for a possible standardization to overcome the empirical use. In the course of our on-going research on Cameroonian medicinal plants used traditionally to treat human microbial infections (Tene et al., 2008a, 2008b; Tamokou et al., 2009), we have investigated phytochemically and biologically the ethyl acetate extract of the stem bark of $C$. macrostachys and isolated five known compounds. These included lupeol (1) (Tene et al., 2004), betulin (2) (Tinto et al., 1992), floridolide A (3) (Puebla et al., 2005), hardwickic acid (4) (McChesney and Silveira, 1989; Murillo et al., 2001) and 12-oxohardwickic acid (5) (Murillo et al., 2001). The in vitro antibacterial and antifungal activities of the extract and compounds 1, 2, 4 and 5 were evaluated.

\section{MATERIALS AND METHODS Experimental}

Melting points (uncorr.) were determined on a Kofler apparatus. Optical rotations were measured on a Polarimeter Perkin-Elmer Modell 343 at $20{ }^{\circ} \mathrm{C}$. ${ }^{1} \mathrm{H}$ NMR (500 or $300 \mathrm{MHz}$ ) and ${ }^{13} \mathrm{C}$ NMR (125 or 75 $\mathrm{MHz}$ ) spectra were recorded at room temperature in $\mathrm{CDCl}_{3}$ using a Bruker Avance500 spectrometer or a Mercury-300 spectrometer. COSY, NOESY, HMQC and HMBC experiments were recorded with gradient enhancements using sine shape gradient pulses. The IR spectra were recorded with a Shimadzu FTIR-8400S spectrophotometer. EIMS $(70 \mathrm{eV})$ were recorded using a combination of $6890 \mathrm{~N}$ Network GC system and 5975 Inert XL Mass Selective Detector (GC-MS). Column chromatography was run on Merck silica gel 60 (70-230 mesh) and gel permeation on Sephadex LH-20 while TLC was carried out on silica gel $\mathrm{GF}_{254}$ precoated plates with detection accomplished by spraying with $50 \% \mathrm{H}_{2} \mathrm{SO}_{4}$ followed by heating at $100{ }^{\circ} \mathrm{C}$, or by visualizing with a UV lamp at 254 and $365 \mathrm{~nm}$.

\section{Plant material}

The stem bark of Croton macrostachys was collected at Bangante, West Province, Cameroon, in September 2007. Authentication was done by Mr Victor Nana, a botanist of the Cameroon National Herbarium, Yaoundé, where the voucher specimen $\left(\mathrm{N}^{\circ}\right.$ 24450/SRF/Cam) is deposited.

\section{Extraction and isolation}

The air-dried and powdered stem bark of C. macrostachys (5 kg) was respectively extracted by percolation with hexane and ethyl acetate for 3 days at room temperature. Evaporation of solvents under reduced pressure yielded $55 \mathrm{~g}$ of hexane extract and 75 $\mathrm{g}$ of EtOAc extract. The hexane extract, mainly oil, was not further investigated in this work. Part of the EtOAc extract (72 g) was subjected to column chromatography (silica gel 60, 70-230 mesh) and eluted with hexane followed by hexane-EtOAc gradient. 30 fractions of $300 \mathrm{ml}$ each were collected and combined on the basis of TLC analysis to afford three major fractions: A (15.5 g; hexane-EtOAc 9:1 and 4:1), B (9.3 g, hexaneEtOAc 7:3 and 1:1) and $\mathrm{C}$ (11 g, EtOAc). Fraction A was further purified on silica gel column chromatography eluted with hexaneEtOAc 19:1, 9:1, 17:3 and 4:1 respectively, to afford lupeol (1) (350 mg), betulin (2) (65 $\mathrm{mg}$ ), floridolide A (3) (2 mg) and complex mixtures of compounds. Fraction B was purified through Sephadex LH-20 gel permeation eluted with $\mathrm{CH}_{2} \mathrm{Cl}_{2}-\mathrm{MeOH}$ (1:1) to give 20 sub-fractions ( $25 \mathrm{ml}$ each). Subfractions 15-20 (2 g) were further combined and purified by repeated preparative TLC, eluted with hexane-EtOAc 7:3, to give hardwickic acid (4) (7 mg) and 12-oxohardwickic acid (5) (20 mg). Additional purifications by column chromatography on Sephadex LH-20 eluted with $\mathrm{CH}_{2} \mathrm{Cl}_{2}(\mathbf{1}, \mathbf{2}$ and 3) and $\mathrm{CH}_{2} \mathrm{Cl}_{2}-\mathrm{MeOH} 9: 1$ and then 1:1 (4 and 5) were required to obtain analytically pure samples. Lupeol (1): white plates from hexane-EtOAc; mp 215-216 ${ }^{\circ} \mathrm{C} ; \mathrm{C}_{30} \mathrm{H}_{50} \mathrm{O}$. Betulin (2): white powder from hexaneEtOAc; mp $237-238{ }^{\circ} \mathrm{C} ; \mathrm{C}_{30} \mathrm{H}_{50} \mathrm{O}_{2}$. Floridolide $\mathrm{A}(3)$ : white powder from hexane-EtOAc; mp 128-130 ${ }^{\circ} \mathrm{C} ; \mathrm{C}_{20} \mathrm{H}_{28} \mathrm{O}_{4}$. Hardwickic acid (4): oil, $[\alpha]_{\mathrm{D}}{ }^{20}-39.6^{\mathrm{O}}\left(\mathrm{CHCl}_{3} ; c 0.83\right) ; \mathrm{C}_{20} \mathrm{H}_{28} \mathrm{O}_{3}$. 12-Oxo-hardwickic acid (5): oil, $[\alpha]_{\mathrm{D}}^{20}-30^{\circ}$ $\left(\mathrm{CHCl}_{3} ; c 0.83\right) ; \mathrm{C}_{20} \mathrm{H}_{26} \mathrm{O}_{4}$.

\section{Antimicrobial activity}

The microorganisms used in this study included three bacterial strains, 
Staphylococcus aureus ATCC 25922, Salmonella typhi ATCC 6539 and Klebsiella pneumoniae ATCC 2091, and two fungal strains, Candida albicans ATCC 24433 and Candida krusei ATCC 6258, obtained from American Type Culture Collection (Manassas, Virginia, USA), in addition to one fungus, Cryptococcus neoformans IP 95026, from Pasteur Institute (Paris, France). The microorganisms were maintained on Nutrient Agar slant for bacteria and Sabouraud Dextrose Agar slant for fungi. The minimum inhibitory concentration (MIC) values were determined by a macro dilution method modified from the one previously described (Gulluce et al., 2003). The inocula were prepared from $18 \mathrm{~h}$ broth cultures of each microorganism, and suspensions were adjusted to $0.5 \mathrm{McFarland}$ standard turbidity. From this suspension, standardized concentrations were made: $10^{6} \mathrm{CFU} / \mathrm{ml}$ for bacteria and $5 \times 10^{5}$ spores $/ \mathrm{ml}$ for fungi. Solutions of the compounds were prepared at a concentration of $1000 \mu \mathrm{g} / \mathrm{ml}$ from which a two-fold serial dilution was made to obtain concentrations ranging from $1000 \mu \mathrm{g} / \mathrm{ml}$ to $0.97 \mu \mathrm{g} / \mathrm{ml}$. The 24-macro-well plates were used and each well contains $940 \mu \mathrm{l}$ of nutrient agar and $10 \mu \mathrm{l}$ of inoculum. One plate was used for each microorganism. Positive control was made of broth and inoculum only, while negative control contains tween 20/acetone in the place of inoculum. A $50 \mu \mathrm{l}$ of each prepared extract/compound at corresponding concentration was then added to each well to obtain $1000 \mu \mathrm{l}$ as the final volume. The plates were incubated, under shaking, at $35^{\circ} \mathrm{C}$ for 24 $\mathrm{h}$ (bacteria) or $48 \mathrm{~h}$ (fungi). Microbial growth in each medium was determined by observing and comparing the test wells with the positive and negative controls. The MIC was defined as the lowest concentration of extract/compound that inhibits the visible growth of microorganisms. $10 \mu \mathrm{l}$ of each well was plated on Mueller-Hinton Agar (bacteria) and Sabouraud Dextrose Agar (fungi) in order to determine the minimum bactericidal or fungicidal concentrations (MBCs or MFCs), which are defined as the lowest concentration yielding negative subcultures or only one colony. All samples were examined in triplicates. Gentamicin (Sigma; St. Louis, MO, USA) and nystatin (Sigma), at the concentration ranging between 250 and 0.97 $\mu \mathrm{g} / \mathrm{ml}$, served as positive controls for antibacterial and antifungal activities respectively.

\section{RESULTS}

The EtOAc extract of the stem bark of C. macrostachys was separated by silica gel column chromatography to give several subfractions which were further purified by open column chromatography to afford lupeol (1) (Tene et al., 2004), betulin (2) (Tinto et al., 1992), floridolide A (3) (Puebla et al., 2005), hardwickic acid (4) (McChesney and Silveira, 1989; Murillo et al., 2001) and 12-oxohardwickic acid (5) (Murillo et al., 2001). Their structures were elucidated on the basis of spectral studies and comparison with published data.

The EtOAc extract and four of the isolated compounds $(\mathbf{1}, \mathbf{2}, \mathbf{4}$ and $\mathbf{5})$ were tested for their antibacterial and antifungal properties (data in table 1). Floridolide A (3), obtained in small amount, was not tested. The extract and the triterpenoids ( $\mathbf{1}$ and $\mathbf{2}$ ) were active against all the microbes used. The diterpenoids ( $\mathbf{4}$ and 5) were inactive against $K$. pneumoniae ATCC 2091 whereas only compound 4 was inactive against $C$. neoformans IP 95026. Betulin (2) and 12-oxo-hardwickic acid (5) were respectively the most antibacterial (MIC $=15.62-31.25 \mu \mathrm{g} / \mathrm{ml}, \mathrm{MBC}=15.62-62.50$ $\mu \mathrm{g} / \mathrm{ml}$ ) and antifungal (MIC $=7.81-31.25$ $\mu \mathrm{g} / \mathrm{ml} ; \mathrm{MFC}=7.81-62.50 \mu \mathrm{g} / \mathrm{ml})$ substances.

\section{DISCUSSION}

All the isolated compounds were previously phytochemically described in the literature. For the antimicrobial properties, we focused our attention on the EtOAc extract, two lupane triterpenoids ( $\mathbf{1}$ and $\mathbf{2}$ ) and two clerodane diterpenoids (4 and 5). Biological activity of lupane triterpenoids had attracted attention as far back as in the $19^{\text {th }}$ century (Tolstikova et al., 2006). For all the microbes used, betulin (2) was more effective than lupeol (1); and, in the case of Staphylococcus aureus ATCC 25922 and Salmonella typhi ATCC 6539, compound 2 showed a relatively good antibacterial activity compared to the reference compound gentamicin. The enhanced activity can be due to the additional hydroxyl group at position 28 in $\mathbf{2}$ (28hydroxylupeol). This is not surprising since lupeol (1) and many of its derivatives 

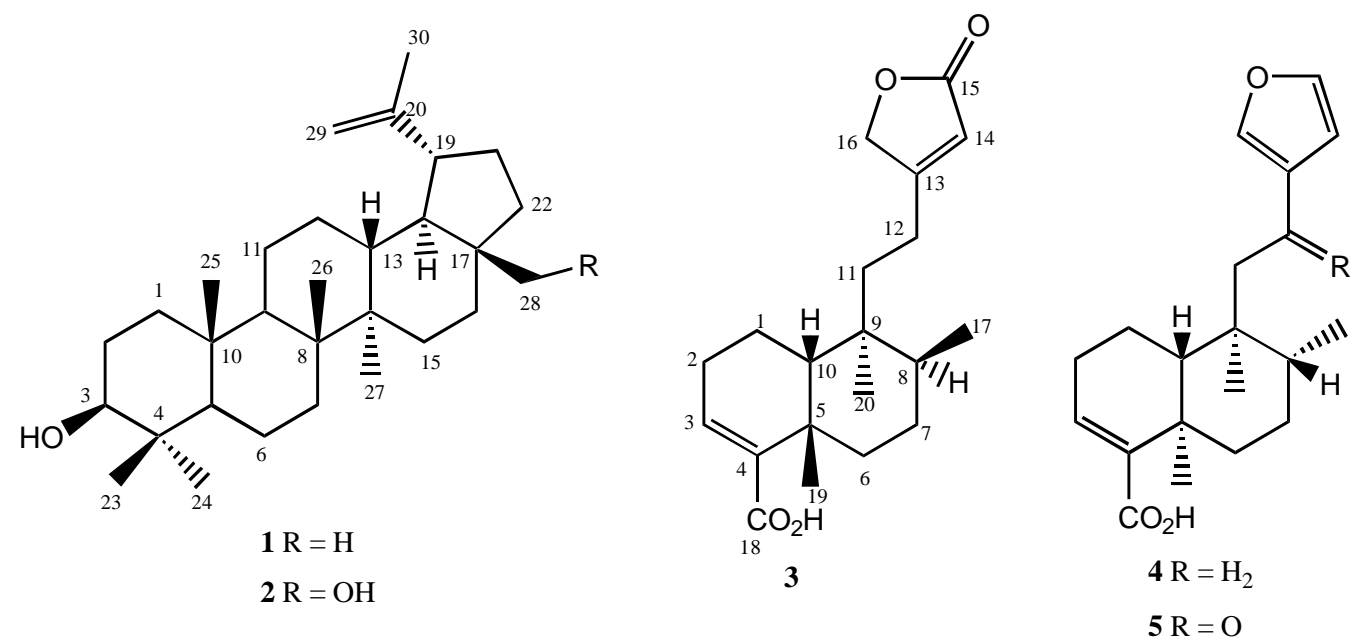

Table 1: Inhibition parameters (MIC, MMC) of the ethyl acetate extract of Croton macrostachys and four of its isolated constituents (in $\mu \mathrm{g} / \mathrm{ml}$ ).

\begin{tabular}{|c|c|c|c|c|c|c|c|}
\hline \multirow{2}{*}{ Test substances } & \multirow{2}{*}{ Parameters } & \multicolumn{3}{|c|}{ Bacterial species } & \multicolumn{3}{|c|}{ Fungal species } \\
\hline & & $\mathbf{S A}$ & ST & $\mathbf{K P}$ & CA & $\mathbf{C K}$ & $\mathbf{C N}$ \\
\hline \multirow{3}{*}{ EtOAc extract } & MIC & 31.25 & 125 & 500 & 62.50 & 250 & 1000 \\
\hline & MMC & 62.50 & 500 & 1000 & 125 & 250 & 1000 \\
\hline & MMC/MIC & 2 & 4 & 2 & 2 & 1 & 1 \\
\hline \multirow{3}{*}{ Lupeol (1) } & MIC & 500 & 1000 & 1000 & 1000 & 500 & 1000 \\
\hline & MMC & 1000 & 1000 & $>1000$ & 1000 & 500 & $>1000$ \\
\hline & MMC/MIC & 2 & 1 & - & 1 & 1 & - \\
\hline \multirow{3}{*}{ Betulin (2) } & MIC & 15.62 & 15.62 & 31.25 & 250 & 125 & 250 \\
\hline & MMC & 15.62 & 62.50 & 31.25 & 250 & 500 & 500 \\
\hline & MMC/MIC & 1 & 4 & 1 & 1 & 4 & 2 \\
\hline \multirow{3}{*}{ Hardwickic acid (4) } & $\mathrm{MIC}$ & 31.25 & 500 & $>1000$ & 62.50 & 250 & $>1000$ \\
\hline & $\mathrm{MMC}$ & 125 & 500 & - & 62.50 & 250 & - \\
\hline & MMC/MIC & 4 & 1 & - & 1 & 1 & - \\
\hline \multirow{3}{*}{ 12-Oxo-hardwickic acid (5) } & MIC & 62.50 & 250 & $>1000$ & 7.81 & 31.25 & 31.25 \\
\hline & MMC & 62.50 & 250 & - & 7.81 & 62.50 & 31.25 \\
\hline & MMC/MIC & 1 & 1 & - & 1 & 2 & 1 \\
\hline \multirow{3}{*}{ Gentamicin* } & MIC & 31.25 & 31.25 & 7.81 & 1 & 1 & 1 \\
\hline & $\mathrm{MMC}$ & 31.25 & 31.25 & 7.81 & / & / & / \\
\hline & MMC/MIC & 1 & 1 & 1 & 1 & 1 & I \\
\hline \multirow{3}{*}{ Nystatin* } & MIC & l & I & I & 1.95 & 1.95 & 3.90 \\
\hline & MMC & I & I & I & 1.95 & 1.95 & 3.90 \\
\hline & MMC/MIC & I & l & I & 1 & 1 & 1 \\
\hline
\end{tabular}


have shown this type of biological activities (Tolstikova et al., 2006). Clerodane diterpenoids are known to possess antitumoral, antibacterial and antifungal activities (Biswanath et al., 2005; Murthy et al., 2005; Urzúa et al., 2006). Excepted for Staphylococcus aureus ATCC 25922, compound 5 was more effective than 4. This can be attributed to the additional oxo-group at position 12 in 5. 12-oxo-hardwickic acid (5) was the most antifungal tested compound, but the results obtained were relatively low compared to those of nystatin, the standard drug used. These activities can also be due to the presence of free acidic group at position 18 in both clerodanes $\mathbf{4}$ and $\mathbf{5}$, since some clerodane diterpenoids with the same basic skeleton (18-Me) showed no antimicrobial/antibacterial activity (Palmeira Junior et al., 2006; McChesney et al., 1991; McChesney and Silveira, 1990). The antimicrobial activity of hardwickic acid (4) is comparable to those previously reported for this compound (Palmeira Junior et al., 2006; McChesney et al., 1991; McChesney and Silveira, 1990). However, 12-oxo-hardwickic acid (5), previously isolated from Croton draco (Murillo et al., 2001) is reported here for the second time, but this is the first report on its biological activities. According to Cowan (1999), terpenes may have the ability to disrupt microbial membrane and this may explain their antimicrobial properties. Our data showed that the response in terms of susceptibility to tested drugs varied among the strains. The differences in susceptibility may be explained by differences in cell wall composition and/or genetic content of plasmids that can be easily transferred among microbial strains (Karaman et al., 2003). According to Carbonelle et al. (1987) a compound with the ratio $\mathrm{MBC} / \mathrm{MIC} \leq 4$ is to be considered bactericidal while a compound with the ratio $\mathrm{MBC} / \mathrm{MIC}>4$ is bacteriostatic. For all the tested compounds the ratios $\mathrm{MBC} / \mathrm{MIC}$ were $\leq 4$, and thus they can be classified as bactericidal agents.

In conclusion, we consider that $C$. macrostachys is a promising antibacterial and antifungal species. In addition, betulin and 12oxo-hardwickic acid were the most active compounds while the most sensitive microorganisms were Staphylococcus aureus ATCC 25922 for bacteria and two Candida species, Candida albicans ATCC 24433 and Candida krusei ATCC 6258, for fungi. These results justified the use of $C$. macrostachys to cure infectious diseases in traditional medicine. Terpenes have a wide spectrum of biological activities and some of them may be useful in medicine. The therapeutic potential of lupeol and betulin was previously reported (Patočka, 2003). However, further study is required to evaluate the effect and toxicity of the tested compounds in experimental animals and to establish if they could be safely used as topical antimicrobial agents.

\section{ACKNOWLEDGEMENTS}

This research was supported by the International Science Program, Uppsala University, Sweden (ISP, Grant No. CAM:02), and, the International Foundation for Science, Stockholm, Sweden, and the Organisation for the Prohibition of Chemical Weapons, The Hague, The Netherlands (IFSOPCW, Grant No. F/4238-1). We are grateful to Prof. K. Krohn of the University of Paderborn in Germany and Dr. H. K. Wabo of the University of Dschang in Cameroon for the record of some NMR spectra. We also thank Mr Victor Nana, a botanist of the Cameroon National Herbarium, for plant identification.

\section{REFERENCES}

Biswanath D, Reddy MR, Ramu R, Ravindranath N, Harish H, Ramakrishna KVS, Rao YK, Harakishore K, Murthy USN. 2005. Clerodane diterpenoids from Pulicaria wightiana. Phytochemistry, 66(6): 633-638.

Block S, Baccelli C, Tinant B, Meervelt LV, Rosenberg R, Jiwan J-LH, Llabrès G, De Pauw-Gillet M-C, Quetin-Leclerq J. 2004. Diterpenes from the leaves of Croton zambesicus. Phytochemistry, 65(8): 1165-1171.

Carbonelle B, Denis F, Marmonier A, Pinon G, Vague R. 1987. Bactériologie Médicale: Techniques Usuelles. Édition SIMEP : Paris; 228-282.

Cowan MM. 1999. Plant products as antimicrobial agents. Clin. Microbiol. Rev., 12(4): 564-582.

Getahun A. 1976. Some common medicinal and poisonous plants used in Ethiopia 
folk medicine. Addis Abeba University, Addis Abeba, Ethiopia.

Gulluce M, Sokmen M, Daferera D, Agar G, Ozkan H, Kartal N, Polissiou M, Sokmen A, Sahin F. 2003. The in vitro antibacterial, antifungal and antioxidant activities of the essential oil and methanol extracts of herbal parts and callus cultures of Satureja hortensis L. J. Agric. Food Chem., 51(14): 3958-3965.

Hutchinson J, Dalziel JM. 1958. Euphorbiaceae. In Flora of West Tropical Africa ( $2^{\text {nd }}$ edn; vol. 1, part 2), Keay RWJ (ed). Crown Agents for Overseas Governments and Administration: London; 394.

Kapingou MC, Guillaume D, Mbwambo ZH, Moshi MJ, Uliso FC, Mahunnah RL. 2000. Diterpenoids from the roots of Croton macrostachys. Phytochemistry, 54(8): 767-770.

Karaman İ, Şahin F, Güllüce M, Öğütçü H, Şengül M, Adigüzel A. 2003. Antimicrobial activity of aqueous and methanol extracts of Juniperus oxycedrus L. J. Ethnopharmacol., 85(2 \& 3): 231235.

Krebs HC, Ramiarantsoa H. 1997. Clerodane diterpenes of Croton hovarum. Phytochemistry, 45(2): 379-381.

Mazzanti G, Bolle P, Martinoli L, Piccinelli D, Grgurina I, Animati F, Mugné Y. 1987. Croton macrostachys, a plant used in traditional medicine: purgative and inflammatory activity. J. Ethnopharmacol., 19(2): 213-219.

McChesney JD, Clark AM, Silveira ER. 1991. Antimicrobial diterpenes of Croton sonderianus. I. Hardwickic and 3, 4secotrachylobanoic acids. J. Nat. Prod., 54(6): 1625-1633.

McChesney JD, Silveira ER. 1989. 12hydroxyhardwickic acid and sonderianial, neo-clerodanes from Croton sonderianus. Phytochemistry, 28(12): 3411-3414.

McChesney JD, Silveira ER. 1990. Entclerodanes of Croton sonderianus. Fitoterapia, 61(2): 172-175.

Mukherjee PK, Saritha GS, Suresh B. 2002. Antimicrobial potential of two different Hypericum species available in India. Phytother. Res., 16(7): 692-695.

Murillo RM, Jakupovic J, Rivera J, Castro VH. 2001. Diterpenes and other constituents from Croton draco (Euphorbiaceae). Rev. Biol. Trop., 49(1): 259-264.

Murthy MM, Subramanyan M, Bindu Hima M, Annapurna J. 2005. Antimicrobial activity of clerodane diterpenoids from Polyalthia longifolia seeds. Fitoterapia, 76(3 \& 4): 336-339.

Ngadjui BT, Abegaz BM, Keumedjio F, Folefoc GN, Kapche GWF. 2002. Diterpenoids from the stem bark of Croton zambesicus. Phytochemistry, 60(4): 345-349.

Palmeira Junior SF, Conserva LM, Barbosa Filho JM. 2006. Clerodane diterpenes from Croton species: distribution and a compilation of their ${ }^{13} \mathrm{C}$ NMR spectral data. Nat. Prod. Comm., 1(4): 319-336.

Patočka J. 2003. Biologically active pentacyclic triterpenes and their current medicine signification. J. Appl. Biomed., 1(1): 7-12.

Puebla P, Correa SX, Guerrero M, Carron R, San Feliciano A. 2005. New cisclerodane diterpenoids from Croton schiedeanus. Chem. Pharm. Bull., 53(3): 328-329.

Tamokou JD, Kuiate J-R, Tene M, Tane P. 2009. Antimicrobial clerodane diterpenoids from Microglossa angolensis Oliv. Et Hiern. Indian J. Pharmacol., 41(2): 60-63.

Tane P, Tatsimo S, Connolly JD. 2004. Crotomacrine, a new clerodane diterpene from the fruits of Croton macrostachyus. Tetrahedron Lett., 45(38): 6997-6998.

Tene M, Tane P, Kuiate J-R, Tamokou JD, Connolly JD. 2008. Anthocleistenolide, a new rearranged nor-secoiridoid derivative from the stem bark of Anthocleista vogelii. Planta Med., 74(1): 80-83.

Tene M, Tane P, Sondengam BL, Connolly JD. 2004. Lignans from the roots of Echinops giganteus. Phytochemistry, 65(14): 2101-2105.

Tene M, Tane P, Tamokou JD, Kuiate J-R, Connolly JD. 2008. Degraded diterpenoids from the stem bark of Neoboutonia mannii. Phytochemistry Lett., 1(2): 120-124.

Tinto WF, Blair LC, Alli A, Reynolds WF, McLean S. 1992. Lupane triterpenoids of Salacia cordata. J. Nat. Prod., 55(3): 395-398. 
Tolstikova TG, Sorokina IV, Tolstikov GA, Tolstikov AG, Flekhter OB. 2006. Biological activity and pharmacological prospects of lupane terpenoids: I. Natural lupane derivatives. Russ. J. Bioorg. Chem., 32(1): 37-49.

Urzúa A, Jara F, Tojo E, Wilkens M, Mendoza L, Trezende MC. 2006. A new antibacterial clerodane diterpenoid from the resinous exudates of Haplopappus uncinatus. J. Ethnopharmacol., 103(2): 297-301.

Yineger H, Yewhalaw D, Teketay D. 2008. Ethnomedicinal plant knowledge and practice of the Oromo ethnic group in Southwestern Ethiopia. J. Ethnobiol. Ethnomed., 4: 11. 